\title{
Corrigendum: Stepping to phase-perturbed metronome cues: multisensory advantage in movement synchrony but not correction
}

\author{
Rachel L. Wright, Laura C. Spurgeon and Mark T. Elliott* \\ School of Psychology, College of Life and Environmental Sciences, University of Birmingham, Edgbaston, Birmingham, UK
}

Keywords: stepping, sensorimotor synchronization, multisensory integration, corrigendum, gait timing

\section{A corrigendum on:}

Stepping to phase-perturbed metronome cues: multisensory advantage in movement synchrony but not correction

by Wright, R. L., Spurgeon L. C., and Elliott, M. T. (2014). Front. Hum. Neurosci. 8:724. doi: 10.3389/fnhum.2014.00724

OPEN ACCESS

Edited and reviewed by: Petri Toiviainen, University of Jyväskylä, Finland

*Correspondence: Mark T. Elliott,

m.t.elliott@warwick.ac.uk

Received: 09 July 2015

Accepted: 20 July 2015

Published: 19 August 2015

Citation:

Wright RL, Spurgeon LC and Elliott MT

(2015) Corrigendum: Stepping to phase-perturbed metronome cues: multisensory advantage in movement

synchrony but not correction.

Front. Hum. Neurosci. 9:441.

doi: 10.3389/fnhum.2015.00441
Due to an oversight, one of the co-author's names was left out of the original article. The list of authors in the original article has now been updated to include Laura C. Spurgeon who made a significant contribution to this study, including its organization and conduct, as well as some aspects of the design.

The Author Contributions section of the original article were also updated to include Laura C. Spurgeon and the Acknowledgments section was further amended as necessary.

The authors regret the earlier omission. This error does not change the scientific conclusions of the article in any way.

The original article has been updated.

Conflict of Interest Statement: The authors declare that the research was conducted in the absence of any commercial or financial relationships that could be construed as a potential conflict of interest.

Copyright ( $\odot 2015$ Wright, Spurgeon and Elliott. This is an open-access article distributed under the terms of the Creative Commons Attribution License (CC BY). The use, distribution or reproduction in other forums is permitted, provided the original author(s) or licensor are credited and that the original publication in this journal is cited, in accordance with accepted academic practice. No use, distribution or reproduction is permitted which does not comply with these terms. 